\title{
Tongue Involvement in Parry-Romberg Syndrome
}

AMIELEENA CHHABRA, MD, Sub Specialty Fellow, Division of Rheumatology, Department of Pediatrics, British Columbia (BC) Children's Hospital, University of British Columbia; JOSEPH M. LAM, MD, FRCPC, Assistant Clinical Professor, Department of Pediatrics, and Associate Member, Department of Dermatology and Skin Sciences, University of British Columbia; WINGFIELD RHEMUS, MD, MPH, Clinical Assistant Professor of Pediatrics, Division of Dermatology, BC Children's Hospital, University of British Columbia, Vancouver, British Columbia, Canada. Address correspondence to Dr. A. Chhabra, Division of Rheumatology, K4-135 Ambulatory building, BC Children's Hospital, 4480 Oak St., Vancouver, British Columbia V5Z 4H4, Canada. E-mail: amieleena.chhabra@cw.bc.ca. Ethical clearance was not required from the institutions' ethics boards for this manuscript, in accordance with the institutional policies. Written and informed consent was obtained from patients/guardians. J Rheumatol 2017;44:1412 doi:10.3899/jrheum.161576

Parry-Romberg syndrome (PRS) is an uncommon disorder characterized by progressive hemiatrophy of the skin and soft tissue of the face. It can also involve atrophy of deeper structures, such as muscles, cartilage, and bones ${ }^{1}$. Intraoral involvement may occur with hemiatrophy of the mandible, teeth, and tongue ${ }^{2}$. We describe striking mucosal involvement of the tongue in 2 girls with PRS. Cases were from the British Columbia Children's Hospital.

A 4-year-old female presented with hyperpigmentation over right chin for 6 months. Examination revealed hyperpigmented plaques above the right ear, behind the right ear extending to the jaw, and over the mental prominence. The right ear lobe and helix were atrophic. Oral examination revealed rightward deviation of the tongue and hemiatrophy with loss of papillae (Figure 1, left panel). Tests for antinuclear antibodies, anti-dsDNA, and Borrelia were negative. Treatment with oral prednisone $5 \mathrm{mg}$ twice daily and $15 \mathrm{mg}$ weekly oral methotrexate (MTX) resulted in no progression of the lesions over 2 years.
A 15-year-old female presented with hypopigmentation and induration of the right paranasal skin. Physical examination revealed an indurated plaque along the right paranasal skin with atrophic plaques extending from the right cheek to the chin and neck. Oral examination revealed hemiatrophy and loss of dermal papillae over the right side of the tongue (Figure 1, right panel). Treatment with $15 \mathrm{mg}$ twice daily oral prednisone and $20 \mathrm{mg}$ weekly oral MTX was initiated with softening and partial resolution of the facial and neck lesions. The oral lesions showed minimal change over the 4-year followup.

\section{REFERENCES}

1. El-Kehdy J, Abbas O, Rubeiz N. A review of Parry-Romberg syndrome. J Am Acad Dermatol 2012;67:769-84.

2. Sommer A, Gambichler T, Bacharach-Buhles M, von Rothenburg T, Altmeyer P, Kreuter A. Clinical and serological characteristics of progressive facial hemiatrophy: a case series of 12 patients. J Am Acad Dermatol 2006;54:227-33.

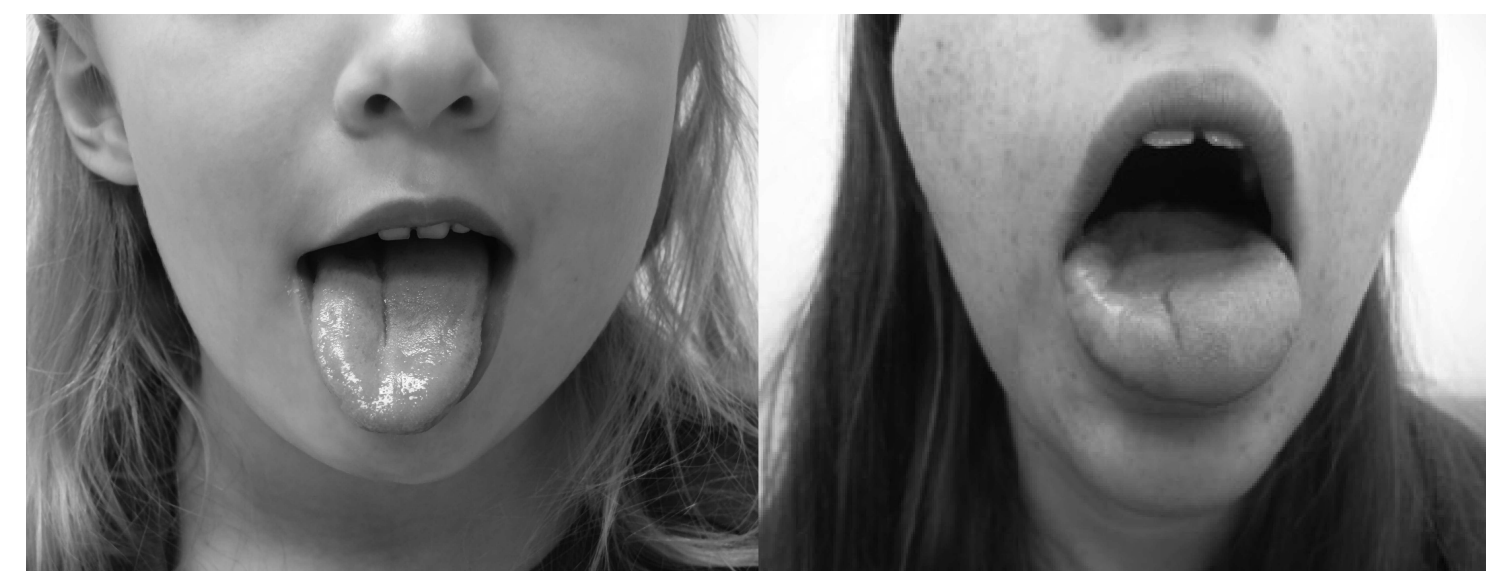

Figure 1. Left panel: hemiatrophy of the right side of the tongue in a 4-year-old girl. Right panel: hemiatrophy and loss of papillae of the right side of the tongue in a 15-year-old female. 